\title{
A Rare Case of Diaphragmatic Mass: The Key to Diagnosis of a Lung Adenocarcinoma
}

\author{
Cláudia Rocha*, Vera Clérigo, Lígia Fernandes, André Rodrigues, Dora Sargento, \\ Glória Silva \\ Serviço de Medicina III, Hospital Pulido Valente, Centro Hospitalar Lisboa Norte, Lisboa, Portugal \\ Email: sudney@hotmail.com
}

Received 20 June 2014; revised 28 July 2014; accepted 26 August 2014

Copyright (C) 2014 by authors and Scientific Research Publishing Inc.

This work is licensed under the Creative Commons Attribution International License (CC BY).

http://creativecommons.org/licenses/by/4.0/

(c) (i) Open Access

\section{Abstract}

Lung cancer is a leading cause of death due to malignancy worldwide. Diaphragmatic metastasis secondary to primary lung cancer is rare. In the literature, only a few cases have been described as the majority of cases of diaphragmatic metastasis which are secondary to gastrointestinal neoplasia. The authors report a rare case of diaphragmmatic metastasis from a primary adenocarcinoma of the lung in a 76-year-old female patient with no history of active or passive smoking with progressive worsening fatigue, asthenia, malaise, and unquantified weight loss with three months of evolution, associated with pleuritic chest pain and edema of the lower limbs for fifteen days previous to hospital admission. Chest $\mathrm{X}$-ray showed elevation of the right hemi-diaphragm and thoracic-abdominal-pelvic computed tomography revealed a complex multilobuled mass with neoformative characteristics intersecting the diaphragm and invading the dome liver and the right lung region. Biopsy of the mass was performed whose histological examination was consistent with moderately differentiated adenocarcinoma. Immunohistochemical examination was positive for cytokeratin 7 and negative forcytokeratin 20, suggesting primary lung tumor. A positron emission tomography was performed without uptake in other locations. Diagnosis of adenocarcinoma with diaphragmatic metastasis was then admitted and the patient started chemotherapy with carboplatin and gemcitabine. The patient died six months after the diagnosis. The authors also present a brief theoretical discussion based on the current and scarce literature on this rare entity.

\section{Keywords}

Diaphragmatic Metastasis, Metastatic Lung Adenocarcinoma, Muscle Metastasis

\footnotetext{
${ }^{*}$ Corresponding author.
}

How to cite this paper: Rocha, C., Clérigo, V., Fernandes, L., Rodrigues, A., Sargento, D. and Silva, G. (2014) A Rare Case of Diaphragmatic Mass: The Key to Diagnosis of a Lung Adenocarcinoma. Advances in Lung Cancer, 3, 62-65. 


\section{Introduction}

Lung cancer is the leading cause of mortality for malignancy worldwide. Annually, 1,350,000 new cases are diagnosed around the world, corresponding to $12.4 \%$ of all malignancies. For Portugal, the overall incidence is 38 per 200,000 and 29 per 100,000 for men and 9 per 100,000 for women. During equivalent period, 1,180,000 patients die each year due to lung cancer, reflecting $17.6 \%$ of the total deaths for malignancy annually. In Western Europe and the United States of America, the mortality rate for lung cancer reaches an approximate equivalent to the sum of deaths owing to cancer of the prostate, breast, pancreas and colon [1].

Approximately $40 \%$ to $50 \%$ of patients have metastatic lung cancer at diagnosis, conducing to higher mortality. The most common sites of metastasis are the pleura, lung parenchyma, bone, liver, central nervous system and adrenal glands [2] [3]. In several studies, lung adenocarcinoma was the histological type most often found in patients with muscle metastasis and diaphragm was the skeletal muscle most frequently involved (8\%), followed by psoasiliac muscle [3].

The authors present a rare case of lung adenocarcinoma with diaphragmatic metastasis and also present a brief theoretical discussion, in the light of the existing and scarce literature on this rare entity.

\section{Clinical Summary}

A 76-year-old female patient, caucasian, domestic, with previous clinical history of primary hypertension and no history of active and passive smoking was admitted to the emergency room for tiredness framed by small efforts, right pleuritic chest pain and marked edema of the lower limbs, with two weeks of evolution. Additionally, the patient reported no selective anorexia and not quantified weight loss with three months. No fever, dyspnea, orthopnoea, productive cough, haemoptysis, gastrointestinal and genitourinary symptoms were described. Physical examination revealed no fever, normal blood pressure and heart rate, a dullness percussion of the basal region of the right hemithorax and auscultation showed abolition of vesicular murmur in lower two thirds of the right hemithorax, with no adventitious sounds. Concerning abdominal palpation, there was a palpable mass in the transition right hypochondrium-epigastrium and a marked edema of the lower limbs. Performed chest radiograph that showed elevation of the right hemidiaphragm (Figure 1), with no signs of condensation.

In view of the image, athoracic-abdominal-pelvic computed tomography (CT) was performed that revealed a complex and multilobuled mass suggestive of neogenesis, intercepting the diaphragm with invasion of the liver invasion (in the domeregion) and pulmonary territory right (Figure 2).

Histological examination of the biopsy of the diaphragm mass was consistent with diaphragmatic metastasis of moderately differentiated adenocarcinoma. Immunohistochemical examination was positive for cytokeratin 7 , negative for both cytokeratin 20 and thyroid transcription factor 1, suggesting primary lung adenocarcinoma (Figure 3).

CYFRA21-1, CA 19-9, NSE and CEA were within the reference values.

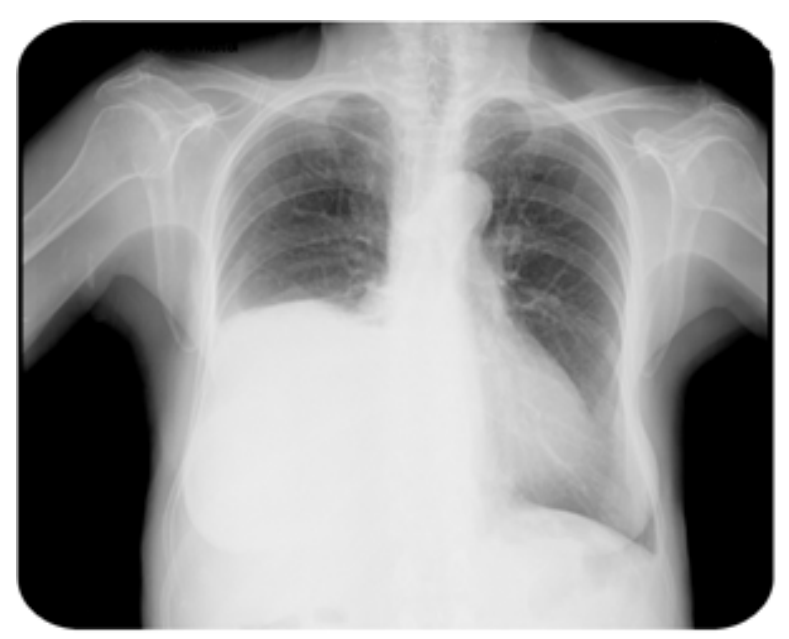

Figure 1. Chest radiograph showed elevation of the right hemidiaphragm. 

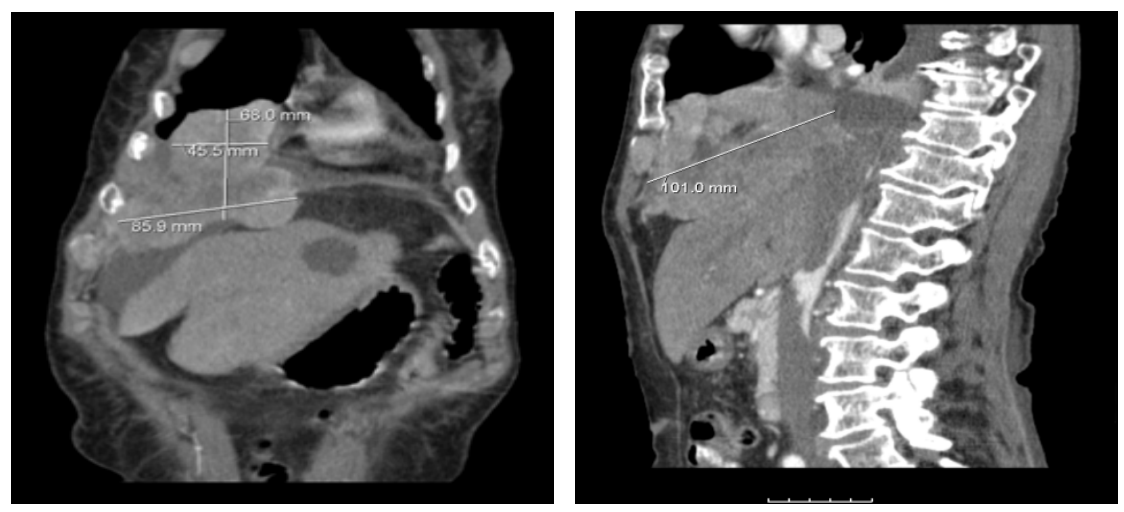

Figure 2. Thoracic-abdominal-pelvic CT revealed a complex and multilobuled mass sugestive of neogenesis intercepting the diaphragm with liver invasion (in the dome region) and right pulmonary territory.
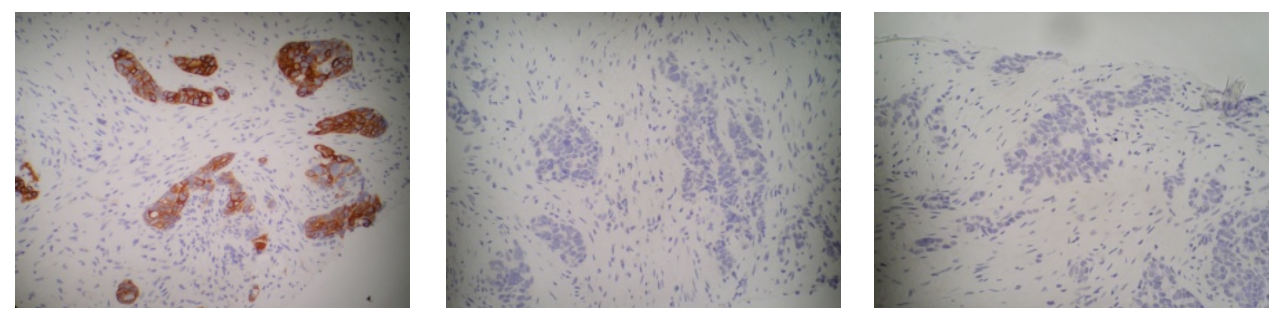

Figure 3. Immunohistochemical examination of the biopsy of the diaphragm mass was positive for cytokeratin 7 and negative for both cytokeratin 20 and thyroid transcription factor 1.

Upon examination results, the case was discussed with pulmonology oncology colleagues, pulmonology and thoracic surgery, which admitted no indication for surgery, and the patient started chemotherapy with carboplatin and gemcitabine (160.0 mg/327.63 mg intravenous). The outcome was unfavourable to tumor progression after five cycles of chemotherapy. Death occurred six months after diagnosis.

\section{Discussion}

Lung cancer despite being the tumour that more metasta sizes to skeletal muscle, that occurrence is considered rare. Several the ories have been proposed to explain this unusual event as the following: skeletal muscle is an adverse environment for tumour cells because of the intermittent contraction of the muscle, lactic acid production and variation of blood flow; skeletal muscle can produce a strong immune response; and the resistance of skeletal muscle to tumour implantation, causes a slow progression of metastatic tumours [3] [4].

The lung adenocarcinoma histological type was the most often found in patients with muscle involvement and the diaphragm was the skeletal muscle most frequently affected (8\%) [4]. However, in the literature, there are few cases of diaphragmatic metastasis secondary to lung cancer, and reports on this rare entity are most often found in association with the presence of gastrointestinal tumors [5]-[7].

The metastasis process described is haematogenous and lymphatic, with cases described of direct extension [4] [8]. Muscle metastases may be identified during the evolution of a known malignancy, or more rarely, may reveal the tumor [4], as in the case presented.

Diaphragmatic metastatic involvement can condition diaphragmatic paralysis and cause dyspnea as seen in our patient. Diaphragmatic paralysisis an uncommon and under-diagnosed cause of dyspnea, mostly when patients are asymptomatic. It is predominantly found incidentally when patients under goradiography of the chest for another reason. The imaging diagnosis is difficult among diaphragm tumors and liver lesions when they are located in the transition from ipsilateral dome. In these cases, biopsy may provide an appropriate diagnosis as with our patient. Treatment for muscle metastases remains unclear. Surgical excision and/or local radiotherapy, sometimes supplemented with chemotherapy, helped to prolong survival in these patients, but this is only achieved after controlling the primary tumor. Studies have shown that in the case of metastatic lung cancer to 
skeletal muscle, the survival rate is considerably reduced in comparison with cases without metastasis, and that regardless of surgical or medical treatment, the presence of muscle metastasis is a sign of poor prognosis [3]. In the case of our patient, even under chemotherapy, there was an adverse progression with spread of disease and death within six months after the diagnosis of the malignancy.

\section{Conclusion}

Metastasis of lung cancer to skeletal muscle is a rare event. The diaphragm is the most affected muscle. Their involvement can condition diaphragm maticparalysis and presence of dyspnea, but may be asymptomatic, and constitute an incidental finding when performing diagnostic imaging of the chest for another reason. Surgical excision can be useful, but in conjunction with medical treatment and control of primary neoplasm. Metastasis presence is a sign of poor prognosis.

\section{References}

[1] Araújo, A.T., Santos, A.C., Gomes, G.P., Barata, F., Munhã, J., et al. (2013) Prevenir a Doença—Acompanhar e reabilitar o doente. Relatório Observatório Nacional das Doenças Respiratórias.

[2] Su, H.T., Tsai, C.M. and Perng, R.P. (2008) Peritoneal Carcinomatosis in Lung Cancer. Respirology, 13, 465-467. http://dx.doi.org/10.1111/j.1440-1843.2008.01268.x

[3] Di Giorgio, A., Sammartino, P., Al Mansour, M., et al. (2004) Lung Cancer and Skeletal Muscle Metastases. The Annals of Thoracic Surgery, 78, 709-711. http://dx.doi.org/10.1016/S0003-4975(03)01364-X

[4] Kwas, H.H., Zendah, I. and Ghedira, H. (2013) Skeletal Muscle Metastases from Lung Cancer. Asian Cardiovascular and Thoracic Annals, 21, 741-743. http://dx.doi.org/10.1177/0218492312470571

[5] Pelin Özcan, K., Gonca, K.G., Oktay, S. and Orhan, Ö. (2011) Rare Thyroid Cartilage and Diaphragm Metastases from Lung Cancer Visualized on F-18 FDG-PET/CT Imaging. Cancer Research and Treatment Molecular Imaging and Radionuclide Therapy, 20, 70-72. http://dx.doi.org/10.4274/MIRT.019882

[6] Jin, S.G., Chen, Z.Y., Chen, W.X., Huang, W., Yan, L.N. and Zeng, Y. (2010) Diaphragmatic Metastases from Colon Carcinoma Mimicking a Hepatic Neoplasm: Report of a Case. Chin Med J (Engl), 123, 1359-1360.

[7] Lee, K.H., Yu, C.S., Namgung, H., Kim, H.C. and Kim, J.C. (2004) Isolated Diaphragmatic Metastasis Originated from Adenocarcinoma of the Colon. Cancer Research and Treatment, 36, 157-159. http://dx.doi.org/10.4143/crt.2004.36.2.157

[8] Kim, M.P. and Hofstetter, W.L. (2009) Tumors of the Diaphragm. Thoracic Surgery Clinics, 19, 521-529. http://dx.doi.org/10.1016/j.thorsurg.2009.08.007 
Scientific Research Publishing (SCIRP) is one of the largest Open Access journal publishers. It is currently publishing more than 200 open access, online, peer-reviewed journals covering a wide range of academic disciplines. SCIRP serves the worldwide academic communities and contributes to the progress and application of science with its publication.

Other selected journals from SCIRP are listed as below. Submit your manuscript to us via either submit@scirp.org or Online Submission Portal.
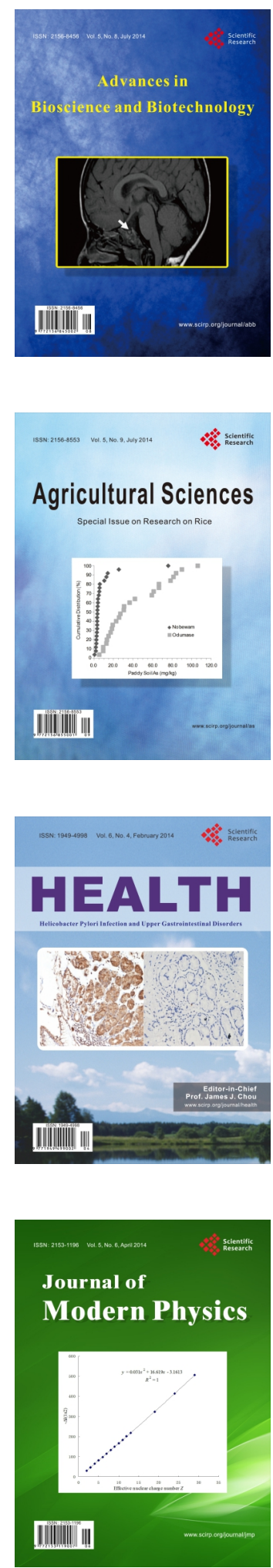
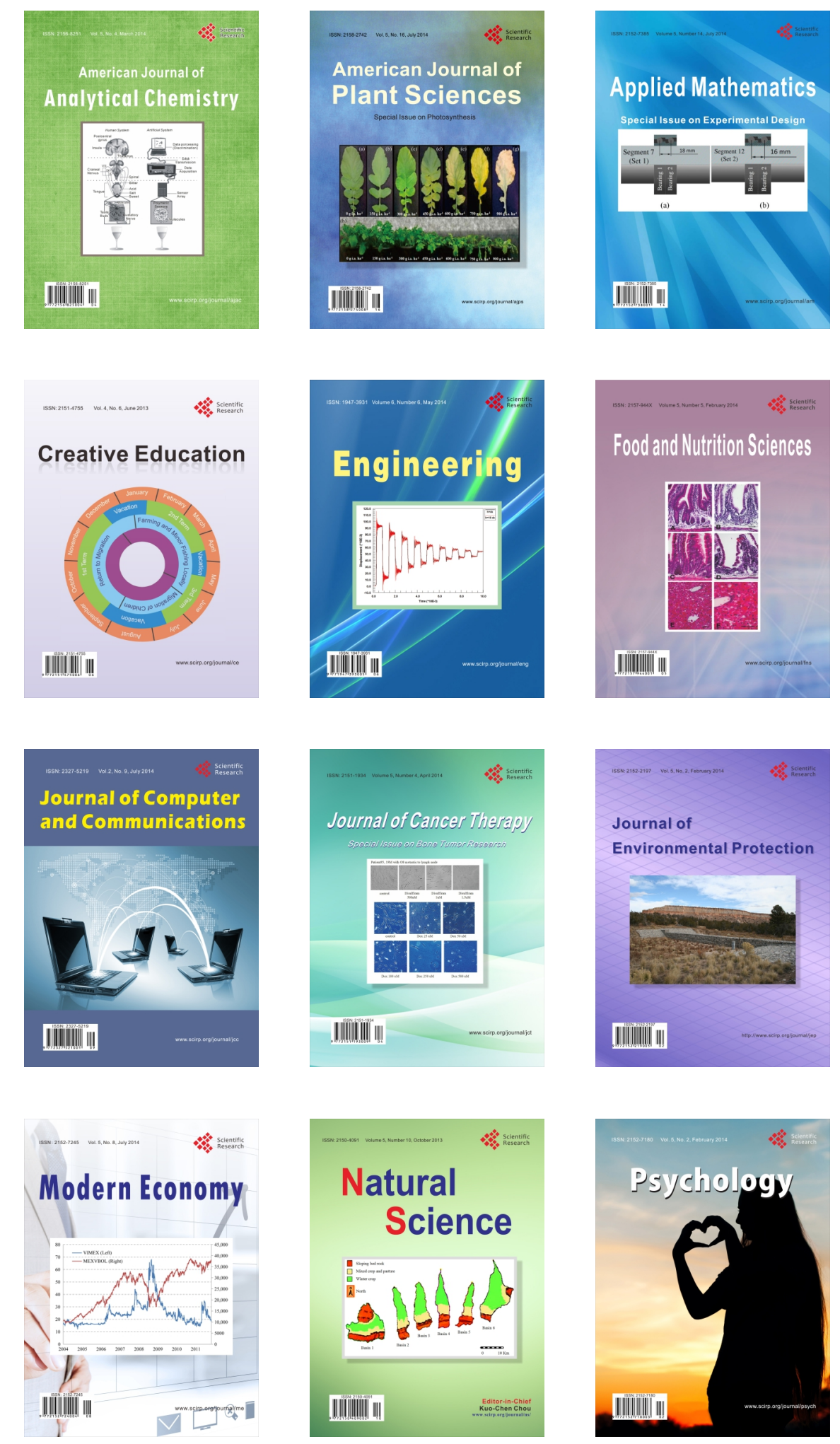